\title{
Analysis of Urban Accessibility of High Speed Railway Based on DEA Index-CTaking Wuhan-Guangzhou High Speed Railway as An Example
}

\author{
He Xuan
}

\author{
School of Economics and Management, Beijing Jiaotong University, China \\ 15120566@bjtu.edu.cn
}

Keywords: DEA; Accessibility; high-speed railway; Economy

\begin{abstract}
With the gradual deepening of the social and economic impact of the high-speed railway, the evaluation of the impact of high-speed railway construction on the pro、vinces and cities along the route (especially the accessibility evaluation) is particularly important. This paper is taking Wuhan - Guangzhou high-speed railway as an example, and combining with the calculation results of four different accessibility indexes, this paper discusses the relative accessibility of the cities along the Wuhan Guangzhou high-speed rail line before and after the completion of the high-speed railway. By comparison, we find that there is a great difference in accessibility between different accessibility metrics. In order to fully consider the changes of city accessibility, this paper introduces data envelopment analysis (DEA) method for the reachability problem into a programming problem, change of accessibility of DEA and establish the accessibility model to calculate the city along the high-speed railway, finally analyzes the differences on the effect of different city of high-speed railway.
\end{abstract}

\section{Introduction}

Transportation is an important supporting force and driving force of sustained and stable growth of the national economy, its development level is restricting the social and economic activities of the depth and breadth and scale, which profoundly affects the development level of different provinces and other related industries. Throughout the world, whether developed or developing countries, the transport capacity and quality of the transportation network is necessary to achieve social production and economic growth. Forslund, Johansson thinks improve the transport network will reduce transportation costs and promote economies of scale and specialization, thereby gaining more benefits [1].

At present, China is vigorously through the planning and construction of high-speed railway to improve the regional cohesion, Meng Deyou believes that high-speed railway has the ability of space reconstruction, which can promote regional economic development and should play an important role in the integration process [2]. Hu Tianjun and Shen Jinsheng point out that the high speed railway to ease the tension, saving transportation plays an important role in the transit time, promote the development of knowledge economy, promote the upgrading of industrial structure, economic integration and providing employment opportunities etc [3].

\section{Literature References}

Accessibility is a relatively difficult concept to define. Morris, J.M, Dumble, P.L argues that accessibility is the convenience of using a given traffic system to arrive at an active location from a given location [4]. Kwan divides accessibility into individual accessibility and local accessibility [5]. The former is a reflection of a good indicator of the quality of life of individuals, the latter refers to the special attributes of all population, easy to reach location or place, and a location is close to "ability. As a result, accessibility in a particular area can be simply defined as convenience to other places. There is no doubt that locational accessibility advantages need to be determined in designated areas and for specific transportation systems. 
The accessibility index can be used to measure the overall welfare of an individual in a region, a family, and an enterprise from a transportation infrastructure. Vickerman shows that reachability generally involves the combination of two elements, nodes and networks [6]. Lu Huapu et al. holds that reachability has five models: space barrier model, cumulative opportunity model, spatial interaction model, utility model and spatio-temporal constraint model [7]. Chen Jie, Lu Feng, Cheng Changxiu systematically classify the reachability measurement methods from the point of view of network characteristics, and find that the influence factors of various accessibility measurement methods are not immutable [8].

Most accessibility indicators contain two relative parts, cost and attractiveness. Cost represents the cost or resistance needed for the flow of goods or persons between two nodes in an established network, which usually has different components, such as distance, travel time, or generalized transport costs. The attractiveness of urban agglomerations can be expressed in terms of population, or expressed by other factors such as employment, or GDP [9]. In most of these studies, the results presented by most methods are generally complementary rather than mutually exclusive. This can be interpreted as the fact that two basic elements of connectedness and interaction constitute the concept of reachability. Bruinsma, Rietveld that is a node exists up to the railway, highway, port, airport, one of them, the accessibility mainly refers to the connectivity, i.e. in the calculation of travel time according to various traffic network rather than along specific traffic network or transport corridor [10]. On the other hand, there are some accessibility indicators focusing on interaction problems, which in principle aim at measuring the difficulty of arrival in different regions.

\section{Accessibility Indicators under Different Scenarios}

\subsection{Wuhan-Guangzhou High-speed Railway}

The Wuhan-Guangzhou high-speed railway is one of the earliest lines for China which play an economically significant role. It will connect the provinces in Central China with the economically developed Pearl River delta. The accessibility change along the Wuhan Guangzhou high-speed railway is chosen as the research object, which has a strong representation and practical significance.

The study takes into account two scenarios: high speed rail and no high speed rail, in which 15 economically active central cities along the Wuhan Guangzhou high-speed rail link are chosen as nodes. In addition, two inter city travel time is according to the length and line two city railway line between the average running speed is obtained, the average speed of the common rail direct express train to $70.18 \mathrm{~km} / \mathrm{h}$ (data source: the original China Ministry of Railways), the average speed of high-speed railway lines for $275.67 \mathrm{~km} / \mathrm{h}$ (data source: 2013.07 China railway timetable). Demographic and GDP data were obtained from statistical yearbook of provinces and regions (2009 and 2011). 
Table1 Wuhan-Guangzhou main routes before and after the passage of time

\begin{tabular}{|l|l|l|l|}
\hline & Distance $(\mathrm{km})$ & Before the time & After the time \\
\hline Changsha-Yueyang & 147 & $1 \mathrm{~h} 16 \mathrm{~min}$ & $32 \mathrm{~min}$ \\
\hline Changsha-Zhuzhou & 52 & $36 \mathrm{~min}$ & $13 \mathrm{~min}$ \\
\hline Changsha-Xiangtan & 78 & $55 \mathrm{~min}$ & $55 \mathrm{~min}$ (noinfluence) \\
\hline Changsha-Hengyang & 186 & $1 \mathrm{~h} 48 \mathrm{~min}$ & $33 \mathrm{~min}$ \\
\hline Changsha-Chenzhou & 333 & $3 \mathrm{~h} 17 \mathrm{~min}$ & $58 \mathrm{~min}$ \\
\hline Yueyang-Zhuzhou & 199 & $2 \mathrm{~h} 1 \mathrm{~min}$ & $48 \mathrm{~min}$ \\
\hline Yueyang-Xiangtan & 225 & $3 \mathrm{~h} 24 \mathrm{~min}$ & $3 \mathrm{~h} 24 \mathrm{~min}$ (noinfluence) \\
\hline Yueyang-Hengyang & 333 & $3 \mathrm{~h} 19 \mathrm{~min}$ & $1 \mathrm{~h} 8 \mathrm{~min}$ \\
\hline Yueyang-Chenzhou & 450 & $4 \mathrm{~h} 58 \mathrm{~min}$ & $1 \mathrm{~h} 38 \mathrm{~min}$ \\
\hline Zhuzhou-Xiangtan & 26 & $27 \mathrm{~min}$ & $27 \mathrm{~min}$ \\
\hline Zhuzhou-Hengyang & 134 & $1 \mathrm{~h} 16 \mathrm{~min}$ & $26 \mathrm{~min}$ \\
\hline Zhuzhou-Chenzhou & 281 & $3 \mathrm{~h} 10 \mathrm{~min}$ & $50 \mathrm{~min}$ \\
\hline Xiangtan-Hengyang & 160 & $2 \mathrm{~h} 6 \mathrm{~min}$ & $2 \mathrm{~h} 6 \mathrm{~min}($ noinfluence) \\
\hline Xiangtan-Chenzhou & 307 & $3 \mathrm{~h} 51 \mathrm{~min}$ & $3 \mathrm{~h} 51 \mathrm{~min}($ noinfluence) \\
\hline Hengyang-Chenzhou & 147 & $1 \mathrm{~h} 32 \mathrm{~min}$ & $30 \mathrm{~min}$ \\
\hline Guangzhou-Chenzhou & 403 & $3 \mathrm{~h} 46 \mathrm{~min}$ & $1 \mathrm{~h} 1 \mathrm{~min}$ \\
\hline Guangzhou-Hengyang & 560 & $5 \mathrm{~h} 9 \mathrm{~min}$ & $1 \mathrm{~h} 33 \mathrm{~min}$ \\
\hline Guangzhou-Zhuzhou & 648 & $6 \mathrm{~h} 32 \mathrm{~min}$ & $2 \mathrm{~h} 16 \mathrm{~min}$ \\
\hline Guangzhou-Changsha & 702 & $7 \mathrm{~h} 7 \mathrm{~min}$ & $2 \mathrm{~h} 32 \mathrm{~min}$ \\
\hline Guangzhou-Xiangtan & 682 & $8 \mathrm{~h} 7 \mathrm{~min}$ & $8 \mathrm{~h} 7 \mathrm{~min}$ (noinfluence) \\
\hline Guangzhou-Yueyang & 830 & $8 \mathrm{~h} 47 \mathrm{~min}$ & $2 \mathrm{~h} 51 \mathrm{~min}$ \\
\hline
\end{tabular}

It can be seen from table 1, after the Wuhan-Guangzhou high-speed railway built, it just takes 1hours and 38 minutes from the northern gate of Hunan Yueyang to the South Gate of Hunan Chenzhou, and the Wuhan to Guangzhou which is along the Hunan area basically can be incorporated into the "2H economic circle", and the cities which are along with Guangzhou has formed a "3H economic circle". It can strengthen inter regional mutual connection and promote the development of the city along.

\subsection{The introduction and calculation of four specific indexes}

In this paper, four different indexes are selected, which reflect different aspects of accessibility. Therefore, the different results of the model only reflect the different conceptualization of reachability. In this sense, no method has absolute advantages or disadvantages.

I. Locational accessibility index

This metric represents the weighted average travel time between the designated city $i$ in each urban cluster and each node:

$$
L_{i}=\frac{\sum_{j=1}^{n} t_{i j} g d p_{j}}{\sum_{j=1}^{n} g d p_{j}}
$$

$L_{i}$ : Locational accessibility index for node $\mathrm{i}$;

$t_{i j}$ : The minimum travel time from node $\mathrm{i}$ to city group $\mathrm{j}$;

This index can reflect the specified city is located in the center of a group of economic 
activities, if the new infrastructure construction in some minimum time path, then the new infrastructure will be reduced to the city through the group travel time to change its location index.

Table2 Weighted mean of travel time index value

\begin{tabular}{|l|l|l|l|l|l|}
\hline Rank & City & $\begin{array}{l}\text { 2009 } \\
\text { (Before the } \\
\text { opening of } \\
\text { Wuhan- } \\
\text { Guangzhou } \\
\text { high speed } \\
\text { railway) }\end{array}$ & $\begin{array}{l}\text { 2010 } \\
\text { (After the } \\
\text { opening of } \\
\text { Wuhan- } \\
\text { Guangzhou } \\
\text { high speed } \\
\text { railway) }\end{array}$ & $\begin{array}{l}\text { Index } \\
\text { changing } \\
\text { value }\end{array}$ & $\begin{array}{l}\text { Accessibility } \\
\text { improvement } \\
\text { rate }\end{array}$ \\
\hline 1 & Changsha & 322.58 & 103.28 & -217.3 & $+67.74 \%$ \\
\hline 2 & Yueyang & 358.92 & 119.77 & -239.15 & $+66.63 \%$ \\
\hline 2 & Hengyang & 230.28 & 72.00 & -157.98 & $+68.80 \%$ \\
\hline 3 & Zhuzhou & 253.54 & 79.76 & -173.78 & $+68.54 \%$ \\
\hline 3 & Chenzhou & 193.78 & 51.67 & -142.11 & $+73.33 \%$ \\
\hline 3 & Xiangtan & 303.36 & 307.36 & +4 & $-1.32 \%$ \\
\hline
\end{tabular}

From the index change of Table 2, the index value of Hengyang is slightly lower than that of Yueyang in the second grade cities, but the accessibility is slightly higher than that in Yueyang. In the third grade in the city, the index value from low to high as follows: Zhuzhou $<$ Chenzhou $<$ Xiangtan, this situation says that Guangzhou to the surrounding areas caused a certain influence.

II. Relative network efficiency index

The relative network efficiency index provides a network efficiency measure for accessibility in the presence or absence of traffic facilities. It is a deviation correction for the limitation of the location reachability index to accessibility. As follows:

$$
A_{i}=\frac{\sum_{j=1}^{n} \frac{t_{i j}}{t_{i j}} g d p_{j}}{\sum_{j=1}^{n} g d p_{j}}
$$

$A_{i}$ : Node i reachability based on network efficiency;

$t_{i j}$ : The minimum travel time from node $\mathrm{i}$ to city group $\mathrm{j}$;

$g d p_{j}$ : The GDP of economic center $\mathrm{j}$;

$\hat{t}_{i j}$ : The imaginary time between the node $\mathrm{i}$ and the node $\mathrm{j}$ after the completion of the new facility (assuming that the high-speed rail is calculated at a speed of $275.67 \mathrm{~km} / \mathrm{h}$ );

$t_{i j} / \hat{t}_{i j}$ : It is a weighted average ratio; According to the target's economic center, the city's $\mathrm{J}$ GDP was calculated.

III. Economic Potential Index

This model is based on the gravity model of the reachability index(E.G. Harris [11]; Smith, Gibb [12]). It can measure potential economic activity to a specific node. The index uses distance decay functions for each city on a plausible weight, taking into account possible interactions between nodes. As follows:

$$
P_{i}=\sum_{j=1}^{n} \frac{g d p_{j}}{d_{i j}^{x}}
$$

$P_{i}$ : Accessibility market potential index of node I; 
$g d p_{j}$ : The GDP of economic center $\mathrm{j}$;

$d_{i j}$ : Urban i and j traffic costs; It is the sum of the travel money cost- $v_{i j}$ and trip time cost- ${ }_{i j}$;

$x$ : Is a parameter that expresses the distance saving benefit function(In this paper, assume $x$ $=1)$.

Table 3 Economic Potential Index Value

\begin{tabular}{|l|l|l|l|l|l|}
\hline Rank & \multicolumn{1}{|c|}{ City } & $\begin{array}{c}\text { 2009 } \\
\text { (Before the } \\
\text { opening of } \\
\text { Wuhan- } \\
\text { Guangzhou } \\
\text { high speed } \\
\text { railway) }\end{array}$ & $\begin{array}{c}\text { 2010 } \\
\text { (After the } \\
\text { opening of } \\
\text { Wuhan- } \\
\text { Guangzhou } \\
\text { high speed } \\
\text { railway) }\end{array}$ & $\begin{array}{c}\text { Index } \\
\text { changing } \\
\text { value }\end{array}$ & $\begin{array}{c}\text { Accessibility } \\
\text { improvement } \\
\text { rate }\end{array}$ \\
\hline 1 & Changsha & 81.25 & 240.35 & 159.1 & $+195.82 \%$ \\
\hline 2 & Yueyang & 81.74 & 231.27 & 149.53 & $+182.94 \%$ \\
\hline 2 & Hengyang & 88.91 & 284.73 & 195.82 & $+220.25 \%$ \\
\hline 3 & Zhuzhou & 158.16 & 426.33 & 268.17 & $+169.56 \%$ \\
\hline 3 & Chenzhou & 82.22 & 294.36 & 212.14 & $+258.01 \%$ \\
\hline 3 & Xiangtan & 144.07 & 149.44 & 5.37 & $+3.73 \%$ \\
\hline
\end{tabular}

From the index change of Table 3, Hengyang is higher than Yueyang in the index change in the second grade cities, and the economic potential of Hengyang is higher. In cities of grade third, the index values are sorted from "high" to "low": Zhuzhou $>$ Chenzhou $>$ Xiangtan. So Zhuzhou is in the best economic potential, Chenzhou times, Xiangtan is ranked two after the city.

\section{Daily Accessibility Index}

DEA is a mathematical programming method to evaluate the relative efficiency of decision units with multiple inputs and multiple output variables in the process of production. Because of the natural heterogeneity of cities, variable scale DEA model is used in this paper. In different scenarios, looking for the front of the envelope consisting of 15 economic centers, searching for effective units from the perspective of accessibility. Cities that do not fall on the frontier of efficiency are considered ineffective, while the measure of accessibility is determined by the outcome of the model.

In this paper, in order to solve the economic center's accessibility index, the location and the network efficiency index can be taken as the input indicators, and the economic potential and daily accessibility as the output indicators. Then, the collection of all economic centers is taken as a reference to study the comparative advantages of a city.

Then by using the following linear programming problem, the reachability DEA efficiency index of each city is calculated:

$$
\begin{gathered}
\max _{\phi, \lambda, s^{+}, s^{-}} z_{0}=\phi+\varepsilon \cdot{ }_{1 s^{+}}^{r}-\varepsilon \cdot{ }^{r} 1 s^{-} \\
Y \lambda-s^{+}=\phi Y_{0} \\
X \lambda+s^{-}=X_{0} \\
r \\
1 \lambda=1 \\
\lambda, s^{+}, s^{-} \geq 0
\end{gathered}
$$


$X:$ Input reachability index matrix;

$Y$ : Output reachability index matrix;

$\phi$ and $\lambda$ : Model intermediate parameters, which express the maximum output ratio of reachability (economic potential, daily accessibility);

$\varepsilon$ : Archimedes constant;

$s$ : Relaxation variable;

Table 4 Accessibility index of DEA- in 15 cities along the route

\begin{tabular}{|l|l|l|l|l|}
\hline \multirow{2}{*}{ City } & \multicolumn{2}{c|}{ Situation } & \multicolumn{2}{c|}{ Variation } \\
\cline { 2 - 5 } & $\begin{array}{l}\text { Before the } \\
\text { high-speed rail } \\
\text { built(2009) }\end{array}$ & $\begin{array}{l}\text { After the } \\
\text { high-speed rail } \\
\text { built(2011) }\end{array}$ & Absolute value & \\
\hline Shenzhen & 0.784 & 0.739 & -0.045 & -5.74 \\
\hline Guangzhou & 1 & 0.862 & -0.138 & -13.80 \\
\hline Yingde & 0.839 & 1 & 0.161 & 19.19 \\
\hline Shaoguan & 0.873 & 0.881 & 0.008 & 0.92 \\
\hline Chenzhou & 0.666 & 1 & 0.334 & 50.15 \\
\hline Leiyang & 0.777 & 1 & 0.223 & 28.70 \\
\hline Hengyang & 0.916 & 0.998 & 0.082 & 8.95 \\
\hline HengMountain & 0.954 & 1 & 0.046 & 4.82 \\
\hline Zhuzhou & 1 & 1 & 0 & 0.00 \\
\hline Changsha & 0.9 & 0.678 & -0.222 & -24.67 \\
\hline Miluo & 0.772 & 0.934 & 0.162 & 20.98 \\
\hline Yueyang & 1 & 0.694 & -0.306 & -30.60 \\
\hline Chibi & 0.706 & 0.788 & 0.082 & 11.61 \\
\hline Xianning & 0.721 & 0.806 & 0.085 & 11.79 \\
\hline Wuchang & 0.615 & 0.623 & 0.008 & 1.30 \\
\hline
\end{tabular}

In the absence of high-speed rail, the higher DEA index cities are Guangzhou, Zhuzhou and Yueyang. After the high-speed rail appeared, the DEA indexes were higher in Britain, Germany, Chenzhou, Leiyang, Heng Mountain and Zhuzhou. Through analysis, we can see that the cities along the high-speed rail in Guangdong and Hunan, near Guangdong, all cities have good relative accessibility. At the same time, in the high-speed railway node cities, most of the cities that can be regarded as accessibility are small and medium-sized cities, such as Britain, Germany, Chenzhou, Heng Mountain and so on.

Conclusion summarizes the available accessibility of Wuhan Guangzhou along the city, in the case of high iron, can find the accessibility of nodes effectively the city into the Anglo German (1), Chenzhou (1), Leiyang (1), Zhuzhou (1), Heng Mountain (1), Miluo (0.934), Hengyang (0.998), the accessibility is good. Great changes of the above conditions, found mainly along the smaller city first belong to this new set of advantages, followed by Guangdong Province, an important city also belongs to the set, accessibility of Chenzhou, Leiyang, Germany, Heng Mountain and Zhuzhou are seen as valid.

In the relative value of change, Britain (19.19\%), Chenzhou (50.15\%), Leiyang (28.70\%), Miluo (20.98\%) were the more influential cities, and all cities have increased by more than $15 \%$. It can be found that all the small and medium-sized cities in Guangdong province and the adjacent cities have been remarkably upgraded. Chenzhou has gained so much improvement because it is situated at the junction of the spillover effects of the core cities of Guangdong and Hunan. The accessibility of Wuhan has not improved significantly since the high-speed rail project was implemented. This is due to the fact that only from the single project of the Wuhan Guangzhou high-speed railway, is it far from the other economic cores.

At the same time, it can be found that the relative accessibility of Shenzhen, Guangzhou, 
Changsha and Yueyang is negative. After the completion of high-speed railway, which is affected by some smaller city accessibility along in the city significantly, such as Germany, Miluo, accessibility to more than the adjacent Shaoguan, Changsha, it may affect the effect of the adjustment of regional industrial structure, population selectivity and enhanced liquidity, industry or enterprise resource allocation and the production and operation of decreasing the cost and other factors, resulting in a certain degree of "siphon effect".

\section{Conclusion}

Taking accessibility as an object, this paper studies the change of high-speed railway to the urban structure along the route. As an important new infrastructure along the line, the new high-speed railway serves a number of the most important economic centers, and studies the complex phenomena of accessibility changes by introducing different measurement methods.

This paper has introduced four different indicators of accessibility (location accessibility, efficiency of network accessibility, daily accessibility and economic indicators, and assuming that the potential) with and without the new high-speed railway two scenarios were compared. Through the calculation, found that there were different index in the special object and the magnitude of the change, the location index and potential index as an example, a change in the range of $60 \%-70 \%$, and another between $170 \%-260 \%$, and the accessibility of Xiangtan city have both positive and negative. Objectively, the four accessibility indexes are different in concept, definition and direction.

After general analysis, this paper uses data envelopment analysis to synthesize four reachability indexes and obtains a comprehensive accessibility index. In the scenario of high-speed railway construction, the DEA accessibility index obtained by the analysis and calculation shows that the small cities such as Germany and Germany have better accessibility. Center city of Guangdong Province, all belong to the accessibility upgrade set, the rest of the site on the line also belong to the set, including Germany, Chenzhou, Leiyang, Heng Mountain, Zhuzhou and other city can be called up to effectively. In addition, there are obvious differences between the DEA index and the first four kinds of indicators, which objectively reflect the general and comprehensive differences.

In a word, reachability is a difficult concept to express accurately. In this paper a comprehensive structural accessibility index only one purpose: planners reachability analysis, due to the different accessibility caused by different measurement results, can be done by using a comprehensive index to alleviate the contradiction caused by different decisions. Taking this paper as an example, according to the regional accessibility characteristics of the new high-speed railway line, we can choose the corresponding angle or square to form a general model, and describe the specific reference. Next, in order to summarize many aspects of information accessibility, can be integrated on the various indicators, so as to obtain a comprehensive accessibility index to more objectively reflect the regional accessibility level, the problem can be abstracted into several constrained multiobjective programming problem of accessibility and reasonable rules, and effectively obtain the comprehensive up to the index of the data envelopment method, namely DEA- accessibility index. This solution model can provide a reference point for other similar "multi factor impact problems" solution.

\section{Reference}

[1] Forslund U M, Johansson B. Assessing road investments: accessibility changes, cost benefit and production effects[J]. The Annals of Regional Science, 1995, 29(2): 155-174.

[2] M.D.You, L.Y.Lin. Influence of high speed railway on accessibility and economic connection of cities along Henan [J]. Geography, 2011, (5):537-543.

[3] H.T.Jun, S.J.Sheng. Analysis of the impact of Beijing Shanghai high speed railway on the economic development along the route [J]. Economic Geography, 1999, (5):101-104.

[4] Morris J M,Dumble P L,Wigan M R. Accessibility indicators for transport planning. 
Transportation Research A.1978, 13: 91-109.

[5] Linneker B J, Spence N A. Accessibility measures compared in an analysis of the impact of the M25 London Orbital Motorway on Britain[J]. Environment and Planning A, 1992, 24(8): $1137-54$

[6] Vickerman R W. Accessibility, attraction, and potential: a review of some concepts and their use in determining mobility [J]. Environment and Planning A, 1974, 6(6): 675-691.

[7] L.H.Pu, W.J.Feng, Z.Y.Bo. Traffic accessibility model and its application in urban traffic planning [J]. Journal of Tsinghua University: Natural Science edition, 2009 (6): 781-785.

[8] C.Jie, L.Feng, C.C.Xiu. Progress in research on methods and applications of reachability measurement [J]. Advances in Geographical Science, 2007, 26(5): 100-110.

[9] Gutiérrez J, Urbano P. Accessibility in the European Union: the impact of the trans-European road network [J]. Journal of Transport Geography, 1996, 4(1): 15-25.

[10] Bruinsma, Rietveld, The European high-speed train network: predicted effects on road accessibility patterns [J]. Journal of transport geography, 1996, 4(4): 227-238.

[11] Harris C D. The, Market as a Factor in the Localization of Industry in the United States[J]. Annals of the association of American geographers, 1954, 44(4): 315-348.

[12] Dundon-Smith D M, Gibb R A. The Channel Tunnel and regional economic development[J]. Journal of Transport Geography, 1994, 2(3): 178-189. 